\title{
De canes, lobos, sierpes y rosas: Berganza y la memoria enmascarada del dios Momo
}

\author{
Alvaro Llosa SANZ*
}

“Aquél [Momo], como era corto de vista, tenía esas ideas sobre los hombres, pero tú has fijado tus ojos en nosotros con mejor vista que Linceo y ves lo de dentro, según parece, a través del pecho; y todo se te revela, hasta el punto de saber no solo que cada uno quiere, sino incluso quién es mejor o peor."

(LuCIANO, Hermotimus 20)

Lope de Vega, en su enciclopédica La Arcadia, recoge por boca del pastor Benalcio una fábula mitológica en la que Júpiter envía al dios Momo a la tierra para obtener de los diversos animales "lo mejor que sus fuerzas alcanzasen" (115). Una larga lista de animales ofrece sus regalos, y se les otorga a cambio los dones que caracterizan su natural comportamiento. Entre ellos, aparece el can:

El perro le ofreció un collar de bronce; diósele en galardón la fidelidad y la memoria, que es tan grande que si anda una vez un camino, de alli a muchos años volverá por él sin errarle, y de aquí mereció que le mandasen criar de los bienes públicos los atenienses. (Lope 116)

Toda la fábula confluye en la historia de la sierpe, símbolo de sabiduría al mismo tiempo que animal ponzoñoso; al regalar ésta a Júpiter una rosa encarnada que ha portado en su boca venenosa, y sospechando el dios que la

* Universidad de Siracusa, NY (USA) 
serpiente habría querido usurpar la belleza de Venus en la flor para disimular así su veneno tras ella, es arrojada al lugar del cielo donde el sol y la luna se juntan en eclipses, y a la rosa misma se la inviste de espinas para que no sea tocada por ninguna otra serpiente. La moraleja que saca uno de los personajes es que "nos debemos guardar de amigos fingidos, lisonjeros, mentirosos y aduladores" (Lope 118).

Voy a establecer un camino que conecta esta fábula y la actividad del dios Momo, más los dones otorgados al can, con la actividad y actitud de denuncia de Cipión y Berganza en el Coloquio de los perros cervantino ${ }^{1}$, publicado en 1614. Me gustaría mostrar cómo estos canes parlanchines lo son bajo el influjo del dios Momo, y desarrollando el don de la memoria al máximo, recuperan sin errarlo todo un camino andado, un auténtico laberinto barroco que se convierte en relato, hasta demostrar ante el lector en mayor dimensión la moraleja de la fábula de la rosa y la serpiente, moraleja que nos remite de nuevo al dios Momo y su famosa crítica a la criatura humana cuando Benalcio propone inicialmente su narración ejemplar a partir de una sentencia del Momus de León Baptista Alberti: "Guárdate del animal hombre, que tiene el pensamiento en lo más escondido del corazón” (Lope 114-15)².

Señala Lope en sus notas eruditas de manual -que tanto molestaban a Cervantes- cómo Momo es "hijo del Sueño y de la Noche, libre satírico y reprehensor de todo"3 (115). El hecho de que, "a la mitad de aquella noche", Campuzano comience a oír a los perros hablar y que, a pesar de saberse desvelado, se plantee en su discusión con Peralta la posibilidad de que todo fuese soñado ${ }^{4}$, ubica el marco del relato en el sospechoso ámbito de actuación de este dios más que ningún otro ${ }^{5}$. Especialmente porque la naturaleza de la conversación a la que Campuzano asiste en mitad de esa noche entronca directamente con la cualidad satírica y reprehensora adjudicada tradicionalmente a Momo. Así pues, si Morfeo suele aparecer como el más famoso dios del

1. Las referencias al Coloquio de los perros y a la novela que lo enmarca, El casamiento engañoso, están tomadas de la edición de Florencio Sevilla Arroyo para la editorial Alianza. Su versión electrónica puede consultarse en la colección Ibero-American Electronic Text series de la Universidad de Wisconsin-Madison: http://digital.library.wisc.edu/1711.dl/IbrAmerTxt.Spa0027.

2. Según Morby, Alberti es el sabio referido, de cuyo libro citado Lope toma la anécdota de origen lucianesco (Hermotimus). Para ver brevemente la influencia de Alberti y el lucianismo a través de él en el Renacimiento, incluida la referencia de Lope, véase Coroleu y su bibliografía.

3. Sebastián de Covarrubias en su Tesoro de la lengua (1611) recoge una genealogía y definición parecida: "fingieron los poetas que de la noche y el sueño nació un hijo, que llamaron Momo. Este no hace cosa alguna, y solo sirve de reprehender todo lo que los demas hacen. Condición de gente ociosa, sin perdonar alguna falta, por pequeña que fuese." (553v)

4. "Y así, muchas veces, después que los oí, yo mismo no he querido dar crédito a mí mismo, y he querido tener por cosa soñada lo que realmente estando despierto, con todos mis cinco sentidos, tales cuales nuestro Señor fue servido dármelos, oí, escuché, noté y, finalmente, escribí, sin faltar palabra, por su concierto." (Cervantes 35).

5. Egido anota la existencia de una tradición de que los perros sueñan (La memoria 478) junto con las afirmaciones que ellos mismos hacen en el Coloquio sobre el caso, y también hace un análisis general de las visiones en los sueños según la época en su artículo sobre el episodio de la cueva de Montesinos, en Egido (Cervantes 141-152). 
sueño, por su ligazón con la irracionalidad dionisiaca, el carácter discursivo crítico de la conversación canina nos inclina a pensar en Momo, que por extensión se lo relaciona con escritores y poetas, aquellos que de manera excelsa crean discursos agudos y bien compuestos ${ }^{6}$.

La traducción del Momus (1450) de Alberti al español por Agustín de Almazán en 1553 inaugura una tradición en lengua castellana en que Momo se transmuta en el uso erasmista de un mito entretenido con función moral (Egido, Las caras 53-57), que a mi parecer hereda Cervantes en su novela ejemplar. Momo es visto, sin embargo, como una figura negativa, por su actividad reprensora sin prudencia alguna, práctica que Cervantes intenta denunciar en el Coloquio al mismo tiempo que le permite no dejar títere con cabeza en el repaso social que hace a través de la vida de perros que sufre Berganza. Esta visión negativa se repite en la aparición de Momo en la Philosophia secreta (1599) de Pérez de Moya donde se lo descalifica además de ser odiado por los dioses debido a su oficio (207r-208r). El padre Vitoria en su manual mitográfico Teatro de los dioses de la gentilidad (1657) lo traza como un necio que al no saber hacer nada ve defectos en todo lo que los demás hacen: "tuvo tan zurdo entendimiento, y tan estragado el gusto, que jamás supo hacer nada, por ser ignorante en sumo grado, y por el consiguiente, el más necio y estólido de los dioses" (556-57). Y Juan de la Cueva dedica una epístola introductoria a sus Comedias (1588) al dios Momo, considerando que su consabida maledicencia aplicada a su libro, lo mantendrá vivo en la memoria de los hombres, y por ello el autor se pone a sus pies: "siguiendo tu natural costumbre, dirás contra él tantas, y tales cosas, las cuales esparcidas por el mundo, forzosamente vendrá a ser eterno por el camino que tú pretenderás desviarlo de la memoria de los hombres, y sepultallo en las tinieblas del Olvido" (4v). Se considera que la murmuración de Momo está omnipresente en la sociedad, como veremos también en el Coloquio cervantino: "no hay lugar por apartado que esté adonde no llegue tu mano, ni deidad a quien reserve tu lengua, por justificada que sea, pues eres fiscal de justos y de injustos, de vivos y muertos, censor de los unos y de los otros, y detractor aun de los mismos dioses" (4v). No hay salvación de sus reprensiones salvo que Momo mismo lo quiera, y lo compara Juan de la Cueva a un perro al que se echa a sus pies para lograr favores: "Con todo esto considerado (si no es falta mi consideración) que serás de la calidad del perro, que no muerde al que se le echa a los pies, quise dirigirlo a tu nombre y ponerlo en tu mano, para obligarte a que desmientas las espías, y que ya que no seas en defendello, por no ir contra tu costumbre, moderes la ira de tu mordaz rigor en su ofensa" (4v-5r). Mientras que Cervantes reconviene en el diálogo canino el vicio de la murmuración, lo aprovecha también como arma erasmiana, tal y como se defendía en el Elogio

6. "Que bien sé que si los tordos, picazas y papagayos hablan, no son sino las palabras que aprenden y toman de memoria, y por tener la lengua estos animales cómoda para poder pronunciarlas; mas no por esto pueden hablar y responder con discurso concertado, como estos perros hablaron. (...) Las cosas de que trataron fueron grandes y diferentes, y más para ser tratadas por varones sabios que para ser dichas por bocas de perros. " (Cervantes 34). 
de la locura (1511): "Prefiero, empero, que los dioses oigan a Momo reprochar sus bellaquerías, ya que de él es de quien antaño las oían con frecuencia” (40). Los canes cervantinos, en la herencia de este quehacer murmurador, son capaces de razonar y sobre todo criticar mediante el uso del habla, en una tradición antigua de animales parlantes que los acerca, al hilo de las investigaciones de Riley, a la sátira menipea de corte lucianesco, en esa dualidad cómico-seria otorgada por la irrealidad del sueño que caracteriza un diálogo clásico como El sueño o El gallo, imitada luego por Cristóbal de Villalón en El Crótalon, y asociada también al El asno de oro de Apuleyo y el Baldo (Alcázar 147 48). Hay que destacar que como perros murmuradores y cínicos en que se van a convertir, según dicen ellos mismos, se acercan a la figura de Diógenes cínico, apodado "el Perro", y rescatada en el renacimiento español por Pero Mexía en su Silva de varia lección (1540) (Alcázar 147). Así, esta murmuración de los perros cervantinos se establece en el marco del sueño satírico de ficción o Somnium, sueño de carácter enigmático capaz de ser interpretado y que se había heredado de Macrobio y Artemidoro: el sueño satírico de ficción se vuelve muy popular desde mediados del siglo XVI en el ámbito europeo (Schwartz).

Lo primero que destacan los perros en el Coloquio es precisamente su capacidad de hablar discursivamente, que asombra a ambos por "ser mayor este milagro en que no solamente hablamos, sino en que hablamos con discurso, como si fuéramos capaces de razón, estando tan sin ella que la diferencia que hay del animal bruto al hombre es ser el hombre animal racional, y el bruto, irracional" (Cervantes 40). Reconocen lo portentoso del caso, como lo hiciera Campuzano al presentar su cartapacio a Peralta antes de su lectura, ya que no se conoce ningún animal que hable con tal capacidad de discurso, a pesar de las cualidades de algunos animales para entender a los humanos ${ }^{7}$. Y lo siguiente que ocurre es que Berganza usa su estrenado discurso racional para satirizar sobre la abundancia innecesaria y portentosa de estudiantes de medicina en la Universidad de Alcalá, hecho que sólo vaticina, o muchos enfermos y una gran calamidad, o muchos médicos muertos de hambre. Se inaugura así la primera de las murmuraciones que Cipión criticará constantemente, y en las que este último, sin darse cuenta, caerá también en ocasiones.

Este planteamiento inicial cercano al disparate, y disfrazado de sueño en aras de la verosimilitud, había hecho reflexionar a Peralta de la cordura de su amigo y se debate si desautorizar su relato ${ }^{8}$. Sin embargo, como explica Egido, la situación del diálogo canino tiene como referente el diálogo renacentista

7. Dice Berganza: “Sé también que, después del elefante, el perro tiene el primer lugar de parecer que tiene entendimiento; luego, el caballo, y el último, la jimia. CIPIÓN.- Ansí es, pero bien confesarás que ni has visto ni oído decir jamás que haya hablado ningún elefante, perro, caballo o mona; por donde me doy a entender que este nuestro hablar tan de improviso cae debajo del número de aquellas cosas que llaman portentos, las cuales, cuando se muestran y parecen, tiene averiguado la experiencia que alguna calamidad grande amenaza a las gentes." (Cervantes 41).

8. "Esto que ahora me cuenta de que oyó hablar los perros me ha hecho declarar por la parte de no creelle ninguna cosa. Por amor de Dios, señor alférez, que no cuente estos disparates a persona alguna, si ya no fuere a quien sea tan su amigo como yo." (Cervantes 34). 
satírico en que un oso y un león discuten de gramática en cierto texto erasmista, en el que los animales hablan con erudición crítica intelectual y gran memoria ${ }^{9}$. La tradición de estos diálogos, tan ligados en su actitud disparatadamente denunciatoria al Elogio de la locura de Erasmo, acercan también al Coloquio, desde su tradición satírica lucianesca, al dios Momo, pues Momo es también imagen representativa de la locura, que en Cervantes vendría tamizada además por un singular aspecto erasmista del Coloquio construido como diálogo lleno de loquacitas a través de cuyo desatino -los perros charlatanesnos presenta una visión crítica de las mezquindades humanas de su época. Un desatino aparente que Cervantes dota de mayor profundidad y trascendencia que la obra escolar erasmista, porque juega a ser novela y narración de una vida, siempre en el límite de la realidad entre la tensión de lo vivido leído y lo vivido recordado, rayando constantemente la frontera de lo verosímil para atraer y entretener a su público al mismo tiempo que darle que pensar ${ }^{10}$. El sueño en que se inserta ofrece además ese tópico barroco de la vida interpretada como Theatrum Orbi, un lugar complejo y difuso de identificar que es representación de algo que no se es pero se busca actuar, de donde nace el afán por el disfraz, el desengaño tras él, la momería teatral o mascarada del hombre, y surge el laberinto de apariencias y disimulos, la gran confusión, que es el caminar por la vida (González García 468 y 473; Rodríguez de la Flor 87-98). Momo es la figura que guiará ese desenmascaramiento.

Para mostrar la visión satírica, el desarrollo discursivo general en el que las murmuraciones de Berganza se inscriben es la propia biografía del can, de un carácter picaresco que ha sido ampliamente demostrado ${ }^{11}$. En su elaboración

9. El coloquio se llama De recta Graeci et Latini sermonis pronuntiatione, de 1528, y señala la lengua como diferenciadora entre hombre y animal. Erasmo justifica el uso del coloquio por la variedad y amenidad posible de argumentos, por la verosimilitusd que otorga a lo dicho, para crear un tratado de gramática vivo. El uso de animales, según Egido, daría además de variedad, una distancia crítica respecto a la materia crítica que se trata. Véase Egido, (La memoria 474 y 479-80). Otras fuentes de inspiración, relacionadas con la fábula esópica y poemas burlescos coetáneos, pueden repasarse en Rodríguez Mansilla (396-97). Riley recupera el coetáneo Crotalón en la línea lucianesca (86).

10. "Palpable vi..., mas no sé si lo escriba, que a las cosas que tienen de imposibles siempre mi pluma se ha mostrado esquiva;

las que tienen vislumbre de posibles, de dulces, de süaves y de ciertas, esplican mis borrones apacibles.

Nunca a disparidad abre las puertas mi corto ingenio, y hállalas contino de par en par la consonancia abiertas.

¿Cómo pueda agradar un desatino, si no es que de propósito se hace, mostrándole el donaire su camino?

Que entonces la mentira satisface cuando verdad parece y está escrita con gracia, que al discreto y simple aplace." (Viaje del Parnaso VI, 49-63)

11. El trabajo de Riley lo aborda junto con la herencia lucianesca. Coroleu (180) destaca además algunos estudios detallados que han conectado la picaresca con el Momus de Alberti, y por tanto la sátira lucianesca en relación con la actitud del dios Momo. 
se demuestra la fama perruna reconocida por Berganza mismo de la "mucha memoria" encarecida en los perros, y también su fidelidad, que en este caso hemos de aplicar a la fidelidad discursiva del relato, ya que la fidelidad a los amos, poco le dura a nuestro perro, siempre buscando un amo mejor ${ }^{12}$. Berganza propone una versión supuestamente fiel a los hechos de su vida, tanto como Campuzano asegura del Coloquio ser una fiel transcripción de lo escuchado: "oí, escuché, noté y, finalmente, escribí, sin faltar palabra" (Cervantes 35). La memoria es la base de ambos para sostener esta postura ${ }^{13}$. Recordemos además la fábula inicial, por la que el perro, gracias a su memoria, "si anda una vez un camino, de alli a muchos años volverá por él sin errarle" (Lope 116). Es lo que propone Cipión a su amigo: "Sea ésta la manera, Berganza amigo: que esta noche me cuentes tu vida y los trances por donde has venido al punto en que ahora te hallas, y si mañana en la noche estuviéremos con habla, yo te contaré la mía" (Cervantes 43). El recorrido biográfico de Berganza a través de su discurso satírico va a ser su ejercicio de memoria como perro sabio: tras años de vivencias es capaz de recuperar punto por punto, y sin errarlo gracias a la cooperación de Cipión ${ }^{14}$, todo un camino andado, un laberinto barroco de identidades y apariencias desenmascaradas, hasta llegar al Hospital de Maúdes, su actual hogar. Esto implica todo un completo ejercicio de arte de la memoria, que se va a ver temperado por toda una teoría del discurso (cómo y de qué manera narrar), y que va a dotar de sentido unitario a todas las escenas hiladas por la memoria ansiosa de Berganza. De ese rico y complejo itinerario me interesa sólo destacar cómo el recorrido memorístico hecho por el perro Berganza es un regreso fiel al punto final donde se halla, husmeando por todos los rincones que halla a su paso, hasta alcanzar al final de la noche y su biografía su hogar y estado actual; al mismo tiempo, su narración a Cipión le permite desvelar o revelar o descubrir o explicar su origen humano a través del episodio central de la bruja.

Berganza siempre había imaginado que sus padres fueron perros alanos, tradicional raza de presa española por su capacidad de retener con sus mandíbulas presas grandes. Sin duda, la de Berganza había de ser raza de alanos carniceros, por lo que narra de su trabajo en el Matadero de Sevilla ${ }^{15}$. Tras

12. Martín señala que Berganza, en su azarosa vida, obtiene los beneficios y tratos especiales de un perro de acuerdo al grupo social en el que se integra, formando parte importante y cumpliendo funciones de acuerdo a la realidad canina de su época, por lo que se aprecia que "los perros no siempre llevaban la proverbial vida de perros" (1566). La fidelidad también proverbial queda en entredicho por Cervantes, no tanto por estos cambios de amo como en especial por ser perro murmurador de todos ellos (Martín 1569). Quizás sea la naturaleza humana de Berganza la que la malogra.

13. Y es mecanismo indispensable, como señala Egido: "Para Campuzano como para los perros, la memoria es alimento del relato y vivir es recordar lo pasado" (La memoria 476).

14. "El texto todo es una prédica y práctica de la contención, incluyéndose observaciones sobre el peligro de la digressio que, dicho sea de paso, atenazaba la novela de aquel tiempo. Es imposible contarlo todo con detalle y, por ello, el perro sabio critica la historia-pulpo a la que le crecen demasiadas colas" (Egido, La memoria 476).

15. Para una brevísima pero significativa historia y clasificación de los alanos, véase Barba, especialmente 554. Para una descricpción con citas histórica y literarias, Parra Gordillo. 
el recorrido por la memoria se descubre que quizás su origen sea humano, al ser el hijo maldito de una bruja, lo que explicaría el portento de poder hablar. Ese es el momento climático de la cuestión individual de la naturaleza de Berganza, que se revela desde entonces como una situación generalizada de metamorfosis entre canes y humanos ${ }^{16}$. Porque este juego de disparatadas metamorfosis entre canes y hombres -sugerida en la cuestión inicial de la racionalidad de unos perros- se ha dado ya en la práctica desde los primeros episodios de la vida de Berganza, en el sentido inequívoco de que numerosos hombres se convierten en auténticos predadores de otros, algo que Berganza ve y sufre como si fuera un humano ${ }^{17}$. Quizás el caso más evidente, y que marca la pauta de lo que será el aprendizaje del perro sobre la bestial naturaleza humana, sea el del falso episodio arcádico, donde se confronta crudamente el idealismo pastoril de las novelas con la realidad diaria española. Si los jiferos del Matadero se comportaban como tales en una dimensión extraordinaria, y robaban y mataban lo mismo "a un hombre que a una vaca" cual auténticos predadores, los pastores se confunden con los lobos: "Pasméme, quedé suspenso cuando vi que los pastores eran los lobos y que despedazaban el ganado los mismos que le habían de guardar" (Cervantes 55). Hay en esto una metamorfosis ya establecida por Ovidio (I.209-243), cuando éste presenta la historia de Lycaon, rey de Arcadia, que para probar la omnisciencia de Júpiter, le da a probar carne humana, y el dios lo condena a convertirse en lobo por el infausto intento de engaño. Lycaon pierde la forma humana y el habla, se convierte en bestia furiosa que sólo desea carne humana. Lycaon, como la sierpe de la otra fábula, es descubierto en su oculta intención. El enlace de este aspecto licantrópico pastoril con el episodio del matadero resulta así más evidente y acentúa el aspecto depredador de aquel lugar de Sevilla donde "no hay res alguna que se mate de quien no lleve esta gente diezmos y primicias de lo más sabroso y bien parado" (Cervantes 45). Si el hombre se presenta como lobo para el hombre -homo homini lupus-, no debería resultar tan extraña la inversión de perro a hombre que sufren Cipión y Berganza. Molho reflexiona que

¿No proclama el Coloquio que el perro es más hombre que el hombre y que, en todo caso, no hay más lobo que el hombre? De hecho, no existe lobo alguno en el espacio del Coloquio, pues los lobos por los que tocan a relato no son sino los mismos pastores, como si las dos licantropías, la negativa y la positiva, se excluyesen recíprocamente. (Molho 26)

16. Señala Riley que "lo que más evidentemente tomó Cervantes de Apuleyo, y con toda probabilidad de Luciano también, era el tema de la metamorfosis humano/animal" (86).

17. Molho (26) habla del perro como lobo casero, de connotaciones positivas, y del lobo como animal de connotaciones negativas, aunque ambos son cánidos. Ve aquí una lucha entre el perro y el lobo, que se concentrará en la relación entre hombre-lobo y hombre-perro. Martín destaca en esta línea de distinción entre perro y lobo, a partir del nombre pastoril de Berganza como Barcino, que "era un nombre popular entre los perros guardianes, y quiere decir beige y blanco, o de color manchado claro. Estos eran colores favorecidos para esos perros ya que así se los podía distinguir por las noches de los lobos" (1565). 
De hecho, es más que probable que toda la raíz del surgimiento del Coloquio, como sueño, delirio, invención de Campuzano o incluso realidad experimentada de alguna manera por él, se asiente sobre esta imagen de la metamorfosis licantrópica y sed lupina del ser humano. La enfermedad que aqueja al alférez, y que le ha dejado hecho casi un desconocido para su amigo Peralta, le ha sido transmitida o dejada en herencia por la mujer que le engañó y a quien, por otra parte, él engañó también, pero a la que finalmente echa de menos y pausiblemente ama ${ }^{18}$. Los síntomas y el tratamiento que recibe Campuzano en el momento de asistir a la charla perruna indican que sufre de sífilis. Y no podemos descartar que las grandes purgas a las que se somete junto a las aflicciones del alma a las que alude nada más salir del hospital no le produzcan un ataque profundo de melancolía ${ }^{19}$. Una de las formas clásicas de la melancolía es, por la presencia de bilis negra en el cerebro, un comportamiento agresivo, bien a modo de licantropía, o bien como dolor de cabeza y sueño (Bartra 32). De hecho, una variante consiste en que el paciente cree haberse convertido en animal, en especial la variedad llamada canina o licantrópica, que es incurable y se caracteriza por poner los ojos amarillos (33). Campuzano sale del hospital quejándose a su amigo de grandes dolores corporales y destaca por "la amarillez de su rostro" (Cervantes 19) ${ }^{20}$. En relación con esto, por general que parezca, la proyección de Campuzano en los perros parlanchines no parece aquí una selección cualquiera, y más parece deberse a alguno de estos fenómenos melancólicos. Campuzano se comporta inicialmente como bizarro soldado que busca los despojos de una mujer a la que le cuesta un tanto conquistar, pero todo el asunto del engaño, el abandono al que es sometido y la sífilis le transforman finalmente en un hombre debilitado y dolido, perro sabio que sólo aspira a que le escuchen su historia, transformada libremente en una invención canina donde lobos y perros muestran sus verdaderas identidades ${ }^{21}$.

18. Rojas interpreta la aventura vital de Campuzano como una peregrinatio paralela a la de Berganza, que debe purificar las culpas de su madre bruja con su vida. Campuzano debe limpiar su pasado de truhán, que por intervención del amor acaba trastocando al soldado valiente que era en débil cuerpo sifilítico, pero interiormente se erige en renovado y hombre sabio tras el aprendizaje. En relación con esta teoría, la visión que propongo es que se convierte de lobo predador en perro sabio tras la experiencia vivida y sufrida.

19. Campuzano, preguntado por su casamiento, asegura que "sabré afirmar que fue por dolores, pues de mi casamiento, o cansamiento, saqué tantos en el cuerpo y en el alma, que los del cuerpo, para entretenerlos, me cuestan cuarenta sudores, y los del alma no hallo remedio para aliviarlos siquiera" (Cervantes 21). La enfermedad del alma asociada a pérdidas amorosas es en tiempos de Cervantes la melancolía.

20. Campuzano es presentado como "un soldado que, por servirle su espada de báculo y por la flaqueza de sus piernas y amarillez de su rostro, mostraba bien claro que, aunque no era el tiempo muy caluroso, debía de haber sudado en veinte días todo el humor que quizá granjeó en una hora" (Cervantes 19). Esta descripción lo acerca a la que da de Momo Baltasar de Vitoria en su Teatro de los dioses de la gentilidad (1657): "Era un hombre macilento, melancólico, flaco, y descolorido, los ojos clavados en el suelo, con un báculo en la mano, y escarbando con él la tierra” (559).

21. También Berganza es engañado por vez primera cuando se deja atraer y seducir por la blanca mano - quizás la misma que atrajo a Campuzano al conocer a su futura mujer- de la mujer ventanera en el matadero, que le roba la carne destinada a otra. La mujer de Campuzano, por los datos que da, 
El dios Momo se representa normalmente con una máscara que está quitándose, para desvelar el auténtico rostro tras las apariencias de los seres. En la fábula misma de La Arcadia de Lope se nos recuerda que fue este dios el que reprendió a Prometeo por que no hubiera creado al hombre con una ventana abierta sobre el alma para ver sus pensamientos, "teniendo por mejor que el pensamiento estuviera en la frente, donde de todos fuera visto" (115). Esa ventana, que alimenta la iconología de la época y cuestiona las políticas del disimulo, simboliza "la adecuación entre pensamiento, palabra y obra, promoviendo un ideal de transparencia que condenaba el simulacro" (Egido, Las caras 59). Un ideal inexistente e inútil en una sociedad que basaba su creciente complejidad en el disimulo, y cuya transparencia como ventana del alma llegó a negar Gracián en El Criticón, perdiendo a Momo entre tanto murmurador mentiroso que hasta lo hace desaparecer ante la confusión general de un indistinguible número de difamadores de la honra de los demás (Egido, Las caras 80). En el Coloquio parecen abrirse estas ventanas bajo el poder murmurador del dios Momo, y sospechamos seres humanos tras los canes, y lobos predadores tras los humanos. Esta situación invertida, muy ligada a la idea del mundo al revés carnavalesco que también representa el dios Momo de la tradición folklórica europea, queda firmemente conectada con la oposición débil/poderoso que establece la profecía de la bruja bajo la que los perros están malditos de nacimiento, donde se establece que los humildes ascenderán cuando caigan los poderosos ${ }^{22}$ : ésta cuestión tiene difícil solución, porque como resume Riley, "los perros se convertirán en hombres tan sólo cuando los hombres dejen de comportarse como bestias. (...) No hay posibilidad de que se regeneren, según la bruja, hasta que la sociedad se vuelque patas arriba" (88). Berganza es víctima de una sociedad que maltrata o menosprecia el ideal del perro doméstico, fiel y defensor del hogar, reflejo de un ser virtuoso cuya imagen queda tan lejana como los pastores arcádicos. A ese perro sólo le queda el vicio extendido de murmurar cuando obtiene el don del habla ${ }^{23}$.

Por criticón sin medida, Momo fue expulsado del Olimpo, y Berganza lo fue también de una casa principal por querer opinar - pensando que podría hablarante un corregidor, actitud que como perro ladrador -así visto por los demás-es más que molesta e indigna de atención. Recordemos que el collar que el can regaló a Júpiter lo somete a sus amos con mejor o peor suerte, como lo demuestra la historia de Berganza. Pero este sometimiento del que no es escuchado por nadie sale a la luz en el Coloquio gracias al milagroso don del habla y uso de

había sido prostituta, lo mismo que indica esta mujer ventanera. Hay un artículo de Álvarez Martínez que trata el comportamiento sexual tan humano implícito en este episodio de Berganza.

22. "Volverán en su forma verdadera / cuando vieren con presta diligencia / derribar los soberbios levantados, / y alzar a los humildes abatidos, / con poderosa mano para hacello" (Cervantes 92). Riley desbroza las asociaciones bíblicas apocalípticas, carnavalescas, subversivas y revolucionarias que suscitaban estos versos en la época (89-91).

23. "Aunque como perro Berganza personifica el ser menos poderoso de todos, y algo menos que un esclavo en la sociedad, al otorgarle habla y la concomitante capacidad de criticar, aunque sea pura "murmuración", Cervantes se asegura de que el subalterno pueda y deba hablar" (Martín 1569). 
la memoria, por los el can que puede narrar su historia y dar relato - en forma humana- a ese sometimiento. El ejercicio de memoria murmuradora desenmascara la falsedad y la maldad humana, la hipocresía que oculta la sed lupina del hombre, y se abren las ventanas del alma por las que atisbamos el engaño al que el hombre, como lobo o bestia, somete a sus semejantes, convirtiéndolos en carne de presa o en perros sometidos. Así, la fábula se convierte en novela de ejemplaridad moral y filosófica, encubierta tras unos personajes traídos en un principio de las fábulas esópicas ${ }^{24}$ que, vestidos de época e inmersos en su tejido social, elevan la moraleja a la reflexión moral mediante un diálogo humanístico hecho novela: se denuncia la vida de perros humillados que espera a cualquier ciudadano virtuoso de cualquier grupo social, ya que aquel que no comparte el extendido y multiforme vicio de aparentar y engañar, sufre todo tipo de menosprecios y palos en la vida; y sólo se propone posible desarrollar plenamente dicha virtud en el retiro social de la caridad cristiana, que es el fin de Berganza en el Hospital con Mahúdes ${ }^{25}$. La idea de regeneración social, de la deseable existencia de un ciudadano virtuoso y humilde -la defensa de un cristiano nuevo, en cierto sentido- se propone como la auténtica víctima, hasta el punto de ser asociado con el demonio, como tras el despertar de la Cañizares se le considera a Berganza ${ }^{26}$. La otra posibilidad es sobrevivir actuando hipócritamente, pero sin daños de terceros, como defiende discretamente comportarse la bruja, que por otro lado, como bruja es el personaje máximo de lo maldito de toda una sociedad corrupta y endiablada que se proyecta en ella ${ }^{27}$.

La murmuración, si bien herramienta útil para que la memoria ironice y desenmascare los defectos sociales, es condenada, como dijimos que Momo lo fue por los dioses. En el Coloquio se presenta como extendido e inevitable vicio, tanto que Berganza lo incluye como pecado original innato: "que el hacer y decir mal lo heredamos de nuestros primeros padres y lo mamamos en la leche" (Cervantes 61). Es la ponzoña de creerse mejor, de pretender arreglar el mundo hablando con críticas dañosas que buscan pasar por bien compuestas razones ${ }^{28}$. La actitud que ofrecen los perros ante esto es, para

24. Riley (85) demuestra esa trayectoria conceptual genérica en el propio texto, que se deduce por los comentarios de los personajes, considerando la historia como una fábula hasta acercarla a la idea de novela.

25. "Berganza escoge una solución religiosa. Se retira del mundo para reunirse con Cipión, dedicando la vida al servicio de los prójimos necesitados. (...) Es la caridad en todos los sentidos de la palabra" (Riley 91).

26. "Con estas razones de la mala vieja, creyeron los más que yo debía de ser algún demonio de los que tienen ojeriza continua con los buenos cristianos, y unos acudieron a echarme agua bendita, otros no osaban llegar a quitarme, otros daban voces que me conjurasen" (Cervantes 100).

27. "Rezo poco y en público, murmuro mucho y en secreto. Vame mejor con ser hipócrita que con ser pecadora declarada: las apariencias de mis buenas obras presentes van borrando en la memoria de los que me conocen las malas obras pasadas. En efeto, la santidad fingida no hace daño a ningún tercero, sino al que la usa. Mira, hijo Montiel, este consejo te doy: que seas bueno en todo cuanto pudieres; y si has de ser malo, procura no parecerlo en todo cuanto pudieres" (Cervantes 95).

28. "CIPIÓN.- ¿Al murmurar llamas filosofar? ¡Así va ello! Canoniza, canoniza, Berganza, a la maldita plaga de la murmuración, y dale el nombre que quisieres, que ella dará a nosotros el de cínicos, que quiere decir perros murmuradores" (Cervantes 66). 
Riley, la actuación con hechos concretos más que el hablar (a diferencia de las grandes soluciones propuestas tan sólo en teoría por los cuatro excéntricos del hospital), y en especial dar ejemplo y no sermonear, muy al contrario de lo que se propone en la picaresca más exitosa de la época, especialmente la del Guzmán, centrada en la maldad irredenta del hombre sobre la que se predica mucho y se hace poco (92-93).

Cipión concibe la actuación bajo un principio filosófico que busca huir de las palabras maldicentes y se centra en el desarrollo de la virtud en todo caso y momento:

La virtud y el buen entendimiento siempre es una y siempre es uno: desnudo o vestido, solo o acompañado. Bien es verdad que puede padecer acerca de la estimación de las gentes, mas no en la realidad verdadera de lo que merece y vale. (Cervantes 118).

Con ella busca superar la simple murmuración burlesca e hiriente de Momo, y quizás actuar como Júpiter, que fue capaz de ver directamente las intenciones de la sierpe ponzoñosa, porque conocía la naturaleza y virtud de lo creado, por lo que actuó para cambiar las cosas y crear así un mundo más perfecto y menos hipócrita. A pesar del pesimismo general del Coloquio, esta última intervención de Cipión, tan obsesionado con la maledicencia aunque sujeto a ella, muestra un atisbo de solución de compromiso personal, porque quizás el comienzo para dar la vuelta a ese mundo viciado y poder alcanzar al fin la profecía -acabando con la maldición que sobre ellos pesa-, sea precisamente dejar de maldecir, es decir, murmurar, de todo el mundo, para cultivar la virtud hasta que resplandezca por sí sola.

El alférez Campuzano, con esta historia en su cartapacio, demuestra haber aprendido y cambiado mucho tras su engañoso casamiento, porque reconoce haber merecido su castigo al haber pretendido engañar, lo mismo que se siente dolido y apaleado por haber sido a su vez engañado ${ }^{29}$ : está claro que no vio la ponzoña contenida en aquella rosa que se le ofreció en forma de hermoso matrimonio, y que contenía en su desengaño el veneno de la sífilis. Pero esta sierpe, también símbolo de la sabiduría y la farmacopea, permite que el lobo predador que era el fiero y aparentemente poderoso alférez cazador de damas purgue mediante su particular peregrinatio canina -vivida o soñada- dicha naturaleza, cuya curación resulta en transformarse en apaleado perro sabio, fiel a su memoria; a través de esta experiencia de carácter fantástico y onírico bajo la noche y el sueño propiciado por el dios Momo, el ejercicio lúdico y encubiertamente disparatado de una memoria murmuradora desenmascara la maldad universal que hace del hombre una bestia, y sobre la que el lector medita tras la lectura del cartapacio.

29. Campuzano reconoce "que el culpado no por conocer su culpa deja de sentir la pena del castigo. Bien veo que quise engañar y fui engañado, porque me hirieron por mis propios filos; pero no puedo tener tan a raya el sentimiento que no me queje de mí mismo" (Cervantes 32). 


\section{BIBLIOGRAFÍA}

Alcázar, Jorge, "La filiación genérica del Coloquio de los perros", Acta poética, 30.1, 2009, 143-63.

Álvarez-Martínez, José Luis, "Berganza y la moza ventanera”, Cervantes: Bulletin of the Cervantes Society of America, 12.2, 1992, 63-77.

Barba, C. J., et alter, "Origen, evolución y situación actual del perro alano español", Arch. Zootec., 47, 1998, 553-56.

Bartra, Roger, Cultura y melancolía. Las enfermedades del alma en la España del Siglo de Oro, Barcelona, Anagrama, 2001.

Cervantes, Miguel de, El casamiento engañoso y El coloquio de los perros, edición de Florencio Sevilla Arroyo y Antonio Rey Hazas, Madrid, Alianza, 1996, 19-119.

Coroleu, Alejandro, "El Momo de León Battista Alberti: Una contribución al estudio de la fortuna de Luciano en España", Cuadernos de Filología Clásica. Estudios Latinos, 7, 1994, 177-83.

Covarrubias, Sebastián de, Tesoro de la lengua castellana o española, Madrid, Luis Sánchez, 1611.

Cueva, Juan de la, "Epístola de dedicatoria a Momo", Primera parte de las comedias y tragedias de Juan de la Cueva, Sevilla, Juan de León, 1588, 3r-5r.

Egido, Aurora, "La memoria ejemplar y El coloquio de los perros", Kurt Reichenberger, ed. Cervantes. Estudios en la víspera de su centenario, Kassel, Edition Reichenberger, 1994, 465-81.

Egido, Aurora, Cervantes y las puertas del sueño. Estudios sobre La Galatea, el Quijote y el Persiles, Barcelona, PPU, 1994.

Egido, Aurora, Las caras de la prudencia y Baltasar Gracián, Madrid, Castalia, 2000.

González García, José M., "Diosa Fortuna e identidades barrocas", Arbor, 743, 2010, 467-78.

Lope de Vega, Félix. La Arcadia, edición de Edwin S. Morby, Madrid, Castalia, 1975.

Martín, Adrienne, "Cervantes y la canifilia renacentista en El coloquio de los perros", Alicia Villar Lecumberri, ed, Peregrinamente peregrinos: Actas del V congreso Internacional de la Asociación de Cervantistas: Lisboa, 1-5 septiembre de 2003, Madrid: Asociación de Cervantistas, 2004, 1559-1574.

Molho, Mauricio, "El sagaz perturbador del género humano": Brujas, perros embrujados y otras demonomanías cervantinas", Cervantes: Bulletin of the Cervantes Society of America, 12.2, 1992, 21-32.

Ovidio, Metamorfosis, Madrid, Cátedra,1995.

Parra Gordillo, Francisco Javier, El alano español. Historia, presente y futuro, ANCAE. www.scrib.com 20/3/2009.

Pérez de Moya, Juan, Philosophia secreta, Zaragoza, Miguel Fortuño Sánchez, 1599.

Riley, Edward C. "La profecía de la bruja (El coloquio de los perros)", Actas del I Coloquio Internacional de la Asociación de Cervantistas: Alcalá de Henares, del 29 de noviembre al 2 de diciembre de 1988, Barcelona, Anthropos, 1990, 83-94.

Rodríguez de la Flor, Fernando, Pasiones frías: secretos y disimulación en el Barroco hispánico, Madrid, Marcial Pons, 2005.

Rodríguez Mansilla, Fernando, "El Coloquio de los perros: de la fábula a la novela", En teoría hablamos de literatura: actas del III Congreso Internacional de Aleph. Granada, 3-7 de abril de 2006, Granada, Dauro, 2007, 396-403.

Rojas Otárola, Jorge, "El camino de la vida como elemento estructural en El casamiento engañoso y Coloquio de los perros de Miguel de Cervantes", Literatura: teoría, historia, crítica, 2, 2000, 143-149. 
Rotterdam, Erasmo de, Elogio de la locura, Madrid, Espasa-Calpe, 1953.

Schwartz, Lía, "De la imaginación onírica y La vida es sueño", Calderón de la Barca y su aportación a los valores de la cultura europea, Centro Virtual Cervantes, 2000. http:// cvc.cervantes.es/literatura/calderon_europa/ 27/11/2012

Vitoria, Baltasar de, Segunda parte del Teatro de los dioses de la gentilidad, Madrid, Juan Antonio Bonet, 1657.

Recibido: 14 de octubre de 2011

Aceptado: 17 de enero de 2013

\title{
Resumen
}

En este artículo busco establecer un camino que conecta el motivo central del perro murmurador en El coloquio de los perros cervantino con una antigua fábula lucianesca cuyo protagonista, el dios Momo, descubre ante Júpiter el carácter fiel y la memoria en el can, mientras que la serpiente se desvela con una perniciosa naturaleza adulatoria y llena de falsedad engañadora. Quiero mostrar cómo estos canes habladores lo son bajo el influjo del dios Momo, divinidad de la sátira y la crítica capaz de ver las ocultas intenciones de los hombres. Mediante el ejercicio de la memoria, Berganza recupera murmurando todo un camino biográfico que se convierte en relato, y muestra ante el lector la moraleja de la fábula de la serpiente acerca de la desconfianza ante las intenciones engañosas entre el género humano.

Palabras clave: Miguel de Cervantes; Coloquio de los perros; dios Momo; sátira; arte de la memoria

Title: About dogs, wolves, snakes and roses: Berganza and the maske of memory of Momus.

\begin{abstract}
This paper establishes a connection between a well-known lucianesque fable and the main topic of the gossipy dog in El coloquio de los perros by Miguel de Cervantes. In the fable, the god of satire and mockery, Momus, uncovers fidelity and memory for dogs, but flattery and deception for snakes. I show how Cervantine dogs are under the sign of Momus: they are able to uncover real and hidden intentions in the heart of each human being. Berganza, exercising satyre and gossiping, unmask amazing cases of falsehood and deception-he exposes his hard life through a picaresque biographical memory, and shows us the deceptive nature of humankind.
\end{abstract}

Keywords: Miguel de Cervantes; Coloquio de los perros; Momus; satyre; Art of memory 